\title{
ALFABETIZAÇÃO: LIMITES E POSSIBILIDADES EM CONVERGÊNCIA NO SÉCULO XXI
}

\author{
LITERACY: LIMITS AND POSSIBILITIES IN CONVERGENCE IN THE 21St CENTURY
}

ALFABETIZACIÓN: LÍMITES Y POSIBILIDADES EN CONVERGENCIA EN EL SIGLO XXI

\author{
Karina Andrade \\ Mestranda em educação - programa de pós-graduação em educação pela Universidade Estadual do Centro \\ E-mail:karinaandgeo@gmail.com. \\ Orcid: https://orcid.org/0000-0001-5895-004X
}

\author{
Poliana Fabíula Cardozo \\ Doutora em geografia pela UFPR. Professora adjunto da Universidade Estadual do Centro-Oeste \\ E-mail: polianacardoz@gmail.com. \\ Orcid: https://orcid.org/0000-0001-5876-1302.
}

\begin{abstract}
RESUMO
Diante dos desafios educacionais contemporâneos, e a partir de análises desenvolvidas em uma pesquisa de pós-graduação stricto sensu em Educação, este trabalho visa refletir, de forma teórico-metodológica, como a alfabetização é configurada no século XXI. Para tal, utiliza-se a perspectiva histórico-estrutural dialética, com base na obra de Triviños (1987). A partir das correlações ciberculturais da atual conjuntura espaçotemporal, somadas às instabilidades educacionais decorrentes da pandemia global, o estudo discute como novas linguagens e realidades de aprendizagem estão sendo abarcadas na alfabetização da geração alpha, por meio das Tecnologias Digitais da Informação e Comunicação (TDIC). Através deste processo, ocorre uma convergência entre abordagens metodológicas, tanto nas políticas públicas educacionais, voltadas à alfabetização, quanto nas políticas voltadas às tecnologias.
\end{abstract}

Palavras-chave: TDIC. Geração alpha. Cibercultura. Multiletramentos. Metodologias ativas.

\begin{abstract}
Given the contemporary educational challenges, and from analyses developed in a stricto sensu graduate research in Education, this work aims to reflect, in a theoretical-methodological way, how literacy is configured in the 21st century. For this purpose, the dialectical historical-structural perspective is used, based on the work of Triviños (1987). From the cyberculture correlations of the current space-temporal conjuncture, added to the educational instabilities resulting from the global pandemic, the study discusses how the new languages and learning realities are being embraced in the alpha generation literacy, through Digital Information and Communication Technologies (DICT). Through this process, there is a convergence of methodological approaches, both in public educational politics, aimed at literacy, and in policies aimed at technologies.
\end{abstract}

Keywords: DICT. Alpha generation. Cyberculture. Multi-literacy. Active methodologies.

\section{RESUMEN}

Ante los retos educativos contemporáneos, y a partir de análisis desarrollado en una investigación de postgrado en Educación, este trabajo tiene como objetivo reflexionar, de forma teórico-metodológica, sobre cómo se configura la alfabetización en el siglo XXI. Para ello, se utiliza la perspectiva histórico-estructural dialéctica, según Triviños (1987). A partir de las correlaciones ciberculturales de la actual coyuntura espaciotemporal, sumada a las inestabilidades educativas derivadas de la pandemia global, este estudio discute la forma como nuevos lenguajes y realidades de aprendizaje están siendo acogidos en el proceso de alfabetización de la generación alfa, con la presencia de las Tecnologías Digitales de la Información y la 
Comunicación (TDIC). Por medio de ese proceso, se produce una convergencia entre acercamientos metodológicos, tanto en las políticas públicas educativas orientadas a la alfabetización, como en las orientadas a la tecnología.

Palabras-clave: TDIC. Generación alfa. Cibercultura. Multialfabetización. Metodologías activas.

\section{INTRODUÇÃO}

A humanidade tem caminhado, cada vez mais, para padrões mundializados, em que tanto os problemas quanto as soluções pedem uma unificação, e encontramos nas técnicas a saída para ambos. Em 2020, o mundo se viu abalado pelo mesmo inimigo comum, invisível como as tantas barreiras que o separa; contudo, cada lugar o combateu de uma forma. Lockdown, confinamento, quarentena, higienização, álcool em gel, máscara, zoonose, distanciamento, isolamento, respirador mecânico, hospital de campanha, assintomático, grupo de risco, mortalidade, pandemia, foram palavras que se tornaram usuais neste período no Brasil. Como uma onda, seus efeitos ressoam em todas as escalas sociais, até os bancos das escolas, as quais permanecem vazias, frias e escuras neste momento, com a incerteza de como e quando será o retorno. Assim, este artigo apresenta como foi a aproximação da alfabetização com as Tecnologias Digitais da Informação e Comunicação (TDIC) ${ }^{1}$, antes deste período, as quais vieram a convergir neste fatídico momento (SANTOS, 2009) - o que demandou reflexões sobre novas formas de aprendizagem.

Com o constante frenesi de mudanças sociais, ocasionadas pelas novas formas de relacionamento que a humanidade passou a ter, em meados do século $\mathrm{XX}$, ao associar técnicas e tecnologias, chegamos, segundo Castells (1999), à era da informação, em uma sociedade interligada via redes. Estes fatores levaram ao florescimento das TDIC, dispositivos eletroeletrônicos que permitem acesso à rede mundial de computadores, a internet (BARANAUSKAS, et al. 2013). Tais tecnologias tomaram tamanha dimensão estrutural na psicosfera ${ }^{2}$ operante que alguns dispositivos técnicos se tornaram quase que indispensáveis ao viver dos cidadãos, seja direta ou indiretamente; isso reverberou nas estruturas institucionais e interpessoais, permeando, por exemplo, o sistema monetário e mercadológico, além de originar novos aspectos para o sistema educacional.

\footnotetext{
${ }^{1}$ Neste trabalho, adota-se TDIC, por ser o termo atualmente adotado pela nova versão da Base Nacional Comum Curricular (BRASIL, 2018). Em trabalhos precedentes encontram-se os termos Novas Tecnologias Informacionais e Comunicacionais (NTIC) ou Tecnologias Informacionais e Comunicacionais (TIC) (BRASIL, 2014).

${ }^{2}$ Conforme Santos (1988), associa-se aos hábitos, anseios, linguagens, manifestações espirituais, modus operandi de uma dada época.
} 
Conforme Lévy (1999), esta nova correlação, entre sociedade e tecnologia, pode ser denominada como cibercultura, a qual originou diferentes expressões da linguagem, com “vocação para intercomunicar e estabelecer interfaces com todos os dispositivos de criação, de registro, de comunicação e de simulação." (LÉVY, 1994, p. 153). Neste sentido, a atribuição de técnicas sobre a linguagem, em face da leitura e da escrita, é denominada alfabetização, destinada a interagir com a língua vernácula, compreender seus usos e regras gerais, suas estruturas gramaticais, semânticas, semióticas e metalinguísticas, a qual permeia os três primeiros anos da escolarização (BRASIL, 2014); no entanto, o termo está tomando uma significância maior, por estar correlacionada a uma crescente multimodalidade textual presente no ciberespaço, associada a ideias de alfabetização e letramento digital.

Sendo assim, é imprescindível que a escola, como uma das instituições responsáveis pela construção e transmissão do conhecimento, além da socialização dos indivíduos, abarque em suas práticas as mudanças político-sociais e culturais pertencentes às dinâmicas da vida no século XXI, de modo que corresponda aos anseios dos estudantes deste espaço temporal. São ele os filhos, netos e bisnetos das gerações do século passado e início deste, a geração $a l p h a^{3}$, compreendendo o período pós 2010, cercados pelo massivo uso das TDIC, por intermédio das telas de smartphones, tablets, computadores, videogames e smart TV (OLIVEIRA, 2019).

Ao problematizar as abordagens que as instituições de ensino estão construindo na fase de alfabetização, no atual momento de pandemia, questiona-se: estas abordagens serão relevantes para a racionalidade que esta geração vivenciará no futuro? Logo, o que podia ser presenciado na realidade da maioria das escolas brasileiras, antes deste acontecimento, foi um engessamento a técnicas ligadas ao século passado, em que a disposição das salas de aulas, permanecia com carteiras enfileiradas, esperando, por parte dos estudantes, disciplina, que tomem nota das atividades, desenvolvam habilidades sobre a linguagem, além de conhecimentos matemáticos, científicos, históricos, geográficos, artísticos, entre outros, em um espaço desconexo do meio técnico-científico-informacional (SANTOS, 2009), que a sociedade presencia desde o final do século XX.

\footnotetext{
3 Segundo Oliveira (2019) o responsável por nomear como geração alpha, primeira letra do alfabeto grego, a geração que nasce pós 2010, foi o sociólogo australiano Mark McCrindle, por tratar-se de uma geração com a viabilidade de iniciar um novo ciclo, vindo a desenvolver novas relações de vida, devido a sua ampla exposição ao ciberespaço.
} 
À vista disto, a alfabetização da sociedade brasileira revelou-se como um sério problema estrutural no século $\mathrm{XX}$, entre idas e vindas de vertentes teóricas que fundamentavam métodos analíticos, sintéticos, até os mistos, além da inconstante estabilidade política, que influencia diretamente os resultados dos índices educacionais do país. Desta forma, por meio de reestruturações que ocorreram com mais significância por volta dos anos 1980, a alfabetização passou a ser associada ao termo letramento. Já no romper do século XXI, em uma perspectiva mais ampla ligada aos multiletramentos, e, por fim, finaliza a segunda década do século XXI associada ao termo literacia (BRASIL, 2019).

Apesar de significativos avanços sociais conquistados no âmbito da alfabetização, esta não teve uma integração expressiva com as TDIC, o que veio a prejudicar o engajamento dos estudantes que, em 2020, conheceram outra face do ensino, em razão da tragédia pandêmica global causada pelo vírus Covid-19. Professores e estudantes de diferentes níveis e modalidades de ensino, forçadamente, tiveram que se adaptar ao modelo cloudding learning environments (MIKROYANNIDIS, 2012), ou seja, ambientes de aprendizagem em nuvem, ajustando as TDIC nas práticas pedagógicas. Tal acontecimento demandou uma readequação das abordagens por parte dos professores, enquanto os estudantes nativos digitais subdividem-se entre o grupo dos que usufruem das TDIC no conforto de suas casas e dos que são completamente excluídos desse processo (PRENSKY, 2001).

Como alternativa ao desengajamento notado nas políticas educacionais ao integrar as TDIC e a alfabetização, propõe-se, neste trabalho, aproximações às metodologias ativas, integrando, conforme Rojo (2017), protótipos didáticos. Objetiva-se a multimodalidade dos recursos comunicativos (VAN LEEUWEN, 2011), como possibilidade de intermediar esta relação nas práticas de professores alfabetizadores em estratégias futuras, a serem desenvolvidas no período pós-pandemia.

\section{Metodologia:}

Esta pesquisa, conforme a obra de Triviños (1987), tem caráter qualitativo, com enfoque histórico-estrutural dialético, o qual usa da descrição para entender as origens, causas, características e mudanças ao longo do tempo sobre o fenômeno analisado, com a finalidade de intuir possíveis caminhos e consequências dele. As primeiras aproximações 
partiram de análises documentais das principais políticas públicas educacionais, a partir dos anos finais do século XX até a segunda década do século XXI, que tratam da alfabetização e das TDIC, em Brasil (1988, 2001, 2007, 2009, 2013, 2014, 2017, 2018, 2019).

$\mathrm{Na}$ segunda etapa, identificado o desenvolvimento das perspectivas destas políticas, foram associadas às obras dos autores que tratam das mudanças sociais causadas pela presença das TDIC, em Castells (1999), Lévy (1994; 1999), Oliveira (2019), Santos (2009); além disso, foram consultados autores que abordam a alfabetização em uma perspectiva histórica e que explicitam suas mudanças metodológicas, como Ferreira Jr (2015), Ferreiro e Teberosky (1985), Frade (2005), Freire (1989), Moratti (2011; 2019), Moreira (2013) e Soares (2004).

Por fim, a terceira etapa consistiu em relacionar as análises, ao desenrolar da alfabetização no momento de pandemia. O intuito é encontrar uma regularidade na desarticulação das TDIC e a alfabetização constatada nas políticas públicas, sugerindo uma aproximação às metodologias ativas neste processo; para tal, agregam-se as obras de Brown e Wyaat (2010), Saccol, et al. (2010), Marcuschi e Xavier (2005), Wing (2006), Dissesa (2001), Csikszentmihaly (1990), Moran e Bacich, (2005), Yahya et. al. (2010), as quais podem resultar, em futuras práticas. Tais práticas podem serem desenvolvidas pelos professores alfabetizadores de maneira mais significativas aos estudantes da geração alpha, construindo a aprendizagem por meio de protótipos didáticos - conforme indica Rojo (2017).

\section{Contextualização dos caminhos da alfabetização no Brasil no século XX:}

A alfabetização incide na "[...] criação ou a montagem da expressão escrita da expressão oral" (FREIRE, 1989, p. 5), vindo a transcrever a oralidade e, [...] levar à aquisição do alfabeto, ou seja, ensinar o código da língua escrita, ensinar as habilidades de ler e escrever. " (SOARES, 1985 p. 20), o que demanda diferentes metodologias para tal finalidade, de modo que contemple suas múltiplas faces. Com isto, “[...] não é um estado ao qual se chega, mas um processo cujo início é na maioria dos casos anterior à escola e que não termina ao finalizar a escola primária. " (FERREIRO, 1999, p. 47), ultrapassando, dessa forma, os limites do âmbito escolar. Apesar da heterogeneidade conceitual, os autores não se limitam em definir a alfabetização apenas em uma técnica, mas um 
processo, com fatores sociais que o determinam e que lhe atribui sentido, pautados no desenvolvimento humano.

Desta maneira, para melhor compreender as multifaces que permeiam a alfabetização, atenta-se o olhar aos seus reflexos do passado. O levantamento histórico sobre a aprendizagem da língua portuguesa brasileira, como herança da vernaculidade dos colonizadores, é um trabalho bastante denso, desenvolvido por inúmeros grupos de pesquisa, os quais contemplam especificidades de todas as regiões do país ao longo do tempo, indicadas, segundo Moratti (2011), como uma história da própria história do Brasil; destarte, demonstra-se que o gênero, etnia e posição social foram preponderantes ao seu acesso, refletidos até os dias de hoje em interesses hegemônicos de outrora, fundamentalismos patriarcais, discriminação e exclusão social.

Moratti (2011) aponta que por mais de cem anos as cartilhas foram um recurso didático presente na aprendizagem da alfabetização no Brasil, considerado por muitos educadores uma receita pronta para alcançar os objetivos esperados da aprendizagem, tendo adaptações conforme as necessidades de cada época. Primeiramente, estas abrangiam os métodos tradicionais sintéticos, influenciados por experiências desenvolvidas predominantemente em países europeus, perdurando com este tipo metodológico até meados da década de 1920. Estes métodos, segundo Frade (2005), partiam de fragmentos menores (letras) para o todo (palavra, frases e textos), definidos como método alfabético, fônico e silábico; tais métodos utilizavam exercícios repetitivos e tinham a memorização como premissa, o que distanciava a significância da linguagem em um contexto mais amplo.

Como "o ato de ler e escrever não se faz sem materialidade" (MORATTI, 2011, p. 195), é preciso atentar o olhar também aos materiais técnicos ou tecnologias utilizados no processo de alfabetização, os quais refletem no proceder das atividades em sala de aula, formulando as didáticas utilizadas pelos professores, reverberando em tradições que perduraram até hoje, podendo desarticular a utilização de tecnologias do tempo presente, pelo engessamento de práticas com aspectos clericais do ensino de séculos passados:

Pode-se dizer, então, que algumas atividades ganham força e tradição pedagógica justamente porque são administráveis num coletivo e com uma materialidade disponível. Supõe-se que algumas delas ultrapassam seu objetivo, em termos de conteúdo, e se tornam canônicas justamente por serem bem administradas na gestão da sala de aula, por permitirem o manuseio de instrumentos e materiais ou por ocuparem os alunos e possibilitarem a administração dos tempos escolares 
(ditado, exercícios de caligrafia, cópia ou outra produção escrita) (MORATTI, 2011, p. 192).

Com o movimento Escola Nova, na década de 1920, experiências, além da Europa e América do Norte, chegam ao Brasil. A nova vertente analítica é composta, segundo Frade (2005), pelo método global de contos, de palavração e sentenciação, chamados métodos globais; de maneira oposta à vertente sintética, a vertente analítica aborda o processo de alfabetização do todo para as partes, ou seja, de estruturas gramaticais mais complexas para mais simples, também abordados em cartilhas.

Até meados da década de 1970, perdurou uma alternância no Brasil e por vezes convergência metodológica na alfabetização, em que os métodos sintéticos e analíticos eram concomitantemente aplicados, vindo a compor os métodos mistos, com bases em variadas vertentes teóricas. Um exemplo, segundo Moreira (2013), é o método natural de aquisição da leitura de forma global, adaptado por Heloisa Marinho e com base na psicolinguística de Freinet. Para Frade (2005), este método implica na aprendizagem da linguagem de maneira espontânea, tendo seus resultados aplicados em atribuições sociais da escrita e da leitura, sendo adaptados anos mais tarde, por teorias construtivistas como método de imersão. Conforme Moreira, o método da Abelhinha também é um exemplo de método misto, o qual adaptava o método fônico, de maneira lúdica, associando o som das letras com personagens de histórias. No entanto, como indica Moratti (2011), por ser embasado em teorias behavioristas, apresentava-se como uma concepção deslocada da linguagem dos indivíduos que a compõe, com metodologias que dissimulam esforços cognitivos.

Apesar de diferentes metodologias aplicadas na alfabetização serem consideradas inovadoras e revolucionárias, repercutindo diretamente em métodos de ensino e viceversa, ainda na década de 1970, como lembra Frade (2005), os índices sobre a defasagem da Educação Básica, sobretudo entre jovens e adultos, eram altos. Assim, a vertente tecnicista, conforme Ferreira Jr (2015), desenvolve uma estratégia, em resposta a movimentos populares, para ampliar o acesso à educação a esta parcela populacional, com o Movimento Brasileiro pela Alfabetização (MOBRAL); contudo, ele foi duramente criticado pelo seu caráter político-ideológico e extinto em meados da década de 1980.

Visto a problemática envolta sobre a acessibilidade da educação, em que os índices de alfabetização representavam decisivas marcas para os países, também nesta época, a 
Organização das Nações Unidas para Educação a Ciência e a Cultura (UNESCO) sugeriu que fossem realizadas avaliações internacionais, sobre as habilidades em relação à leitura e à escrita (SOARES, 2004), refletindo na estruturação de metas e políticas futuras. Assim, a Constituição brasileira de 1988, em seu artigo 214, previa como uma de suas metas decenais a articulação de políticas educacionais, para a erradicação do analfabetismo no país (BRASIL, 1988). Logo, era preciso superar os discursos teóricos e agir na prática, pois a acessibilidade confrontava-se com a qualidade do ensino, como indica Ferreira Jr. (2015), não representando uma garantia plena do aprendizado, somados, ainda, à evasão escolar, o que compromete ainda mais seu desenvolvimento.

A partir de 1980, uma nova vertente começa a fluir sobre a alfabetização brasileira, com o "[...] conceito de letramento, e concomitante desinvenção da alfabetização" (SOARES, 2004, p. 5), apesar deste termo ser conhecido e usual em países como França, Inglaterra, Estados Unidos e Portugal desde o século XIX. O letramento implicava, portanto, fazer da leitura e da escrita uma prática social, como processo contínuo, no qual os indivíduos ampliam o entendimento sobre o mundo ao seu redor, de forma consciente e autônoma, sem se limitar apenas a aspectos da aquisição das técnicas, motoras e orais (SOARES, 2004).

A desinvenção da alfabetização indicada pela autora, com o aparecimento do letramento, significava uma perda de especificidade do processo de alfabetização em relação aos resultados calamitosos que representou até então, percebido em "[...] índices de precário ou nulo desempenho em provas de leitura, denunciando grandes contingentes de alunos não alfabetizados ou semialfabetizados depois de quatro, seis, oito anos de escolarização." (SOARES, 2004, p. 9). Estas discussões levaram os termos alfabetização e letramento, em muitas produções científicas brasileiras, se fundirem e até se confundirem por muito tempo. Todavia, o letramento representa um processo diferente da alfabetização, mas não pode estar desassociado dela:

Dissociar alfabetização e letramento é um equívoco porque, no quadro das atuais concepções psicológicas, lingüísticas e psicolingüísticas de leitura e escrita, a entrada da criança (e também do adulto analfabeto) no mundo da escrita ocorre simultaneamente por esses dois processos: pela aquisição do sistema convencional de escrita - a alfabetização - e pelo desenvolvimento de habilidades de uso desse sistema em atividades de leitura e escrita, nas práticas sociais que envolvem a língua escrita - o letramento. Não são processos independentes, mas interdependentes, e indissociáveis: a alfabetização desenvolvesse no contexto de 


\begin{abstract}
e por meio de práticas sociais de leitura e de escrita, isto é, através de atividades de letramento, e este, por sua vez, só se pode desenvolver no contexto de e por meio da aprendizagem das relações fonema-grafema, isto é, em dependência da alfabetização. A concepção "tradicional” de alfabetização, traduzida nos métodos analíticos ou sintéticos, tornava os dois processos independentes, a alfabetização - a aquisição do sistema convencional de escrita, o aprender a ler como decodificação e a escrever como codificação - precedendo o letramento o desenvolvimento de habilidades textuais de leitura e de escrita, o convívio com tipos e gêneros variados de textos e de portadores de textos, a compreensão das funções da escrita (SOARES, 2004, p. 14-15, grifos da autora).
\end{abstract}

Esta questão só foi esclarecida, de acordo com Brasil (2007), com o fascículo do Programa Pró-letramento, explícito nos materiais produzidos pelo MEC posteriormente; postulava-se que não se escolhe entre alfabetização ou letramento, enfatizando que o que deve se tomar como referência é a associação de ambos, ou seja, alfabetizar letrando. Além desta discussão, que na época não havia solução, Soares (2004) aponta que a alfabetização, neste período, deixou de ser associada a um método, passando a associarse a uma teoria, o construtivismo, com base em Piaget (1973); assim, passou-se a considerar o indivíduo ativo na construção do conhecimento. Neste contexto, a psicogênese da língua escrita, proposta por Ferreiro e Teberosky (1985), seguindo esta concepção de pensamento, buscou, conforme Frade (2005): construir o conhecimento no processo de aprendizagem com os estudantes, por meio experimentações e hipóteses, sem repressões quanto ao erro; apresentar durante o processo de aprendizagem a diversidade textual que permeia a sociedade; diagnosticar o nível de aprendizagem dos estudantes antes de iniciar o processo de ensino e acompanhar seu desenvolvimento; propiciar formas dos estudantes expressem o que sabem, de modo que os professores conheçam diferentes formas de interpretar os resultados.

O método que Ferreiro e Teberosky (1985) compuseram, para testar as hipóteses de escritas, classificava as hipóteses de escrita do estudante do nível pré-silábico, ao silábico com valor, passando para o silábico-alfabético e, por fim, o alfabético. Estas classificações foram tomadas como padrão de sondagem, para se trabalhar especificamente com os estudantes e estavam, inclusive, em orientações de formações do MEC até meados da segunda década do século XXI, representando:

Uma teoria psicolingüística (que explicita como os aprendizes organizam psicologicamente a aprendizagem de um conteúdo de escrita) e não uma teoria pedagógica sobre como ensinar. No entanto, mesmo que as práticas dos professores construtivistas ainda não estejam devidamente organizadas para configurar um método pedagógico, o chamado construtivismo parece adotar 
princípios gerais dos métodos natural e de imersão, embora reconhecendo a necessidade de abordar unidades menores de análise, como a letra, o fonema ou a sílaba (FRADE, 2005, p. 41).

Outro método que ficou conhecido por adaptar a vertente teórica construtivista foi o método Paulo Freire, que defendia uma educação que se desvencilhasse do modo bancário de ser, voltada, sobretudo, à andragogia, dos marginalizados do processo educativo - ao longo dos anos. Logo, a alfabetização ganhou um caráter político, sendo um ato de conhecimento e pensamento criador, possibilitando a reescrita da realidade, como indica Freire (1989), ao considerar fatores externos, como índices econômicos e socioculturais, que refletiam nos resultados do processo de alfabetização, questão ainda latente nesta época.

Soares (2004) resume então, de forma geral, que os paradigmas teóricos, que permearam a alfabetização a partir da segunda metade do século $X X$, podem ser considerados entre 1960 e 1970, uma tendência behaviorista; eles foram, então, substituídos pela tendência cognitivista nos anos de 1980, vindo a avançar em 1990 para o paradigma sociocultural, com a tendência socioconstrutivista. A década de 1990 é marcada, também, pelas reformas neoliberais, como aponta Ferreira Jr. (2015), que levaram a um salto quantitativo da acessibilidade; no entanto, tais reformas não representaram o domínio da língua vernácula, pela grande defasagem de aprendizagem. Assim, o autor indica que o Brasil iniciou o século XX como uma sociedade agrícola e o terminou com uma sociedade urbana e industrial; contudo, não deu aos seus cidadãos as possibilidades de enfrentarem, de maneira equivalente, os desafios culturais, científicos e tecnológicos, necessários ao viver do século XXI, mesmo abordando a alfabetização como um bem cultural, há mais de cem anos.

\section{A (Des)Integração das TDIC na Educação Básica}

A história que se desenha sobre as políticas públicas referentes à instauração das TDIC no ensino no Brasil, mais especificamente na educação básica, é recente, tendo em média 30 anos, refletindo desde sua denominação. Antes disso, as TDIC permeavam o âmbito educacional de forma mais restrita, com ênfase no ensino superior. Nascimento (2013) aponta que desde meados da década de 1970 pesquisadores de diversas universidades e departamentos, do Sul ao Norte do Brasil, com os recursos que eram 
disponíveis, a cada ano, vinham trabalhando no desenvolvimento de softwares, organização de cursos e disciplinas de pós-graduação para formação de professores em TDIC; houve, também, formulação de projetos-piloto, que originaram subprojetos de aplicabilidade das TDIC no ensino em suas múltiplas faces, organização e participação de convenções, eventos nacionais e internacionais para troca de saberes. Eles participaram ativamente de lutas e entraves, criando movimentos ergonômicos em prol das TDIC nas secretarias educacionais estaduais e municipais, o que contribuiu para que elas chegassem à educação básica.

Em quase três décadas de lutas, criou-se, em 1997, o programa que efetivamente alcançou a rede básica de ensino, o Programa Nacional de Informática na Educação (Prolnfo), que disseminou e promoveu as TDIC como uso pedagógico em escola urbanas e rurais em todo Brasil. A partir deste, foi possível levar gradativamente às escolas laboratórios de informática, equipados com computadores com o sistema operacional Linux Educacional. O programa permanece vigente, porém, em 2007, teve uma nova roupagem, passando a ser denominado Programa Nacional de Tecnologia Educacional (Prolnfo), integrando recursos, em estratégia conjunta com a União, estados e municípios, com o intuito de promover a inclusão digital pelo uso de recursos digitais (NASCIMENTO, 2013).

Neste sentido, Nascimento (2013) aponta que o uso das TDIC deve ser organizado pela proposta pedagógica de cada escola, seja como complementação de conteúdos por disciplina ou através de projetos que integrem diferentes disciplinas; assim, a carga horária de uso do laboratório de informática fica a critério dos coordenadores escolares, estruturando-os conforme as possibilidades das infraestruturas de cada escola. Destarte, este contato com as TDIC pode ser: sistematizado, em períodos semanais ou quinzenais, recomendado a escolas em processo inicial de implementação do uso do computador, caracterizando o reforço ou complementação de conteúdos; ou, não-sistematizado, quando os professores familiarizados com as TDIC as integram em seu plano de trabalho, ficando livres para agendar horários no laboratório, integrando o trabalho com diferentes disciplinas. Mesmo com as duas possibilidades, o que se vê nas políticas educacionais é uma frouxidão que pende para o contato sistematizado às TDIC:

As tecnologias da informação e comunicação constituem uma parte de um contínuo desenvolvimento de tecnologias, a começar pelo giz e os livros, todos podendo apoiar e enriquecer as aprendizagens. Como qualquer ferramenta, 
devem ser usadas e adaptadas para servir a fins educacionais e como tecnologia assistiva; desenvolvidas de forma a possibilitar que a interatividade virtual se desenvolva de modo mais intenso, inclusive na produção de linguagens. Assim, a infraestrutura tecnológica, como apoio pedagógico às atividades escolares, deve também garantir acesso dos estudantes à biblioteca, ao rádio, à televisão, à internet aberta às possibilidades da convergência digital (BRASIL, 2014, p. 25).

A inclusão digital, a interatividade virtual nas práticas escolares para a criação de novas linguagens, apresenta-se na maioria das escolas como apoio pedagógico, permeado pelo Prolnfo, contemplando na realidade, como aponta Nascimento (2013) laboratórios de informática ociosos, o que demandaria dos professores um envolvimento maior a ocupar este espaço, requerendo versatilidade, criatividade e tempo. Assim, conforme dados do INEP de 2016, em todas as instâncias do ensino básico, o uso do computador como recurso administrativo superou o percentual disponível por estudante. O acesso à internet dos estabelecimentos de ensino fundamental anos iniciais correspondem a 61,3\%, do ensino fundamental anos finais, 81,0 \%, e, do ensino médio, 94,5\%; logo, os menores índices, tanto para conectividade quanto por computadores por estudante e acesso a laboratórios de informática ficaram para os anos iniciais do ensino fundamental (BRASIL, 2017), que abarca a fase da alfabetização.

O que chama atenção nesses dados é que justamente nesta fase, a qual compreende os estudantes da geração alpha, os quais nascem imersos no mundo cibercultural, serem os menos favorecidos desta racionalidade. Segundo Oliveira (2019), muitos destes, antes mesmo de estarem alfabetizados, já digitam seus nomes com facilidade em dispositivos tecnológicos, navegam em vídeos com loopings infinitos na web, tem acesso a jogos, aplicativos, encontrando mais dificuldades em praticar a caligrafia, o que requer certa técnica sobre a técnica; ou seja, domínio motor e psicolinguístico, entre o lápis e a escrita. Entende-se que esta não é a realidade de todos, porém integrar as TDIC também nesta fase, como alternativa, adaptando avaliações, auxiliando estudantes com Transtorno do Espectro Autista (TEA) e Transtorno de Déficit de Atenção e Hiperatividade (TDAH), entre outras formas, poderia ampliar múltiplas oportunidades de aprendizagem, pois, atualmente, mais se escreve ou se digita? Até quando continuar ensinando as crianças a escrever como no século passado? Quantas vezes por dia paramos para escrever, sem que seja para realizar alguma atividade relacionada ao ensino, ou trabalho específico? As profissões do futuro, requisitarão tal técnica? 
Apesar dos diferentes índices de acessibilidade e conectividade, e todos os questionamentos que surgem sobre o ensino no presente, é inegável que este primeiro passo, de 23 anos com o Prolnfo, teve frutos significativos. No entanto, ainda há dificuldade na integração dos conteúdos nos planos político-pedagógicos e em consonância com novas tendências de letramentos do século XXI; esta é uma barreira invisível, mas presente desde os anos finais do século XX, a qual tornou-se mais explícita em razão da pandemia.

\section{Alfabetização e multimodalidade: fronteiras de uma nova era}

Ler e escrever de forma mecânica, sem entender sua aplicabilidade social, revelouse extremamente insuficiente em relação às demandas educacionais até o final do século XX, vindo a convergir no século XXI, com outro tipo de demanda da alfabetização, a digital; esta é uma nova forma de aprender também seletiva, como foi a alfabetização no início do século XX. Assim, nos últimos anos do século XX, os documentos educacionais brasileiros deram um primeiro passo em seus diálogos, tendo em vista avanços científicos e tecnológicos que a sociedade global passava. Em razão destas mudanças culturais, ocasionadas pelo avanço da globalização e as TDIC, nesta época também, segundo Rojo (2010), manifestou-se a Pedagogia dos Multiletramentos, definida por um grupo de pesquisadores; eles estavam preocupados com o rumo de práticas pedagógicas em relação às novas necessidades que permeavam os letramentos, pois, no século XXI, a alfabetização passou a ser associada, além do letramento, aos multiletramentos, compostos pelas múltiplas manifestações de textos que circulam entre as diferentes culturas, sendo verbais, escritos, digitais e audiovisuais - que interagem entre si e convertem-se em modelos híbridos (ROJO, 2010).

No início do século XXI, a mais expressiva estratégia para a alfabetização, por parte do MEC, foi com foco no Programa Formação de Professores Alfabetizadores (PROFA), tendo como base a concepção construtivista da língua, observando a aprendizagem dos estudantes, respeitando as suas fazes do aprendizado. Esta nova formação não cita mais métodos a serem seguidos, mas didáticas aplicadas primeiramente com os professores, para que estes as replicassem com os estudantes, desenvolvendo atividades permanentes, mediante sequências didáticas ou pedagógicas interdisciplinares, as quais estimulavam a curiosidade, contemplando diversas áreas (BRASIL, 2001). 
Apesar destas propostas representarem novas dinâmicas, são cabíveis questionamentos, em vista de como ainda se desenhava o ensino básico brasileiro neste período. A formação criticava improvisações por parte do professor, que deveria seguir orientações metodicamente para cumprir suas metas de aprendizagem com os estudantes; nesse contexto, não se considerava se o educando teve ou não formação adequada, a heterogeneidade das salas de aula e os desafios das classes multisseriadas e dos recursos, que não se distribuíam e ainda não se distribuem por igual nas escolas de centros urbanos, áreas rurais, quilombolas, indígenas, faxinalenses, itinerantes e da Educação Especial.

Assim, Rojo (2010) indica, que preferencialmente nas práticas dos multiletramentos, deveriam ser incorporadas na aprendizagem, além das técnicas usuais do processo, como papel, lápis, caneta, giz, lousa e materiais impressos, ferramentas que incorporassem áudio, vídeo e edição digital, demandando didáticas diferenciadas que estimulem a análise e produções sociocríticas pelos estudantes, pois a diversidade presente nos ambientes síncronos (online) podem articular saberes formais e informais, caracterizando uma aprendizagem permanente. O desafio era, então, aproximar a multimodalidade do ensino.

Cerca de 10 anos depois do manifesto dos multiletramentos, são constituídas pela Unesco (2009) concepções para formação dos professores em TIC, baseada em teorias econômicas, as quais vinculam a melhoria do ensino em relação ao desenvolvimento econômico, implicando três fatores: o primeiro é a alfabetização tecnológica, com o intuito expandir o conhecimento tecnológico dos estudantes, incorporando habilidades tecnológicas no currículo; o segundo, aprofundar e aprimorar os conhecimentos, aplicando-os na resolução de problemas do mundo real; e, o terceiro, a criação de conhecimentos, potencializando habilidades, para serem inovadores em suas carreiras profissionais, o que possibilita um benefício mútuo entre a sociedade.

Estes princípios norteavam documentos educacionais de alguns países, como o Estados Unidos, despontando a Educação em mídia, já no início do século XXI, como apontam Thoman e Joolls (2003), defendendo uma noção ampliada de alfabetização e de letramento digital, a fornecer estrutura para acessar, analisar, avaliar e criar mensagens em multimeios, desenvolvendo habilidades de investigação e autoexpressão. Essa noção mais ampliada de alfabetização foi sendo discutida e tomando corpo nas atualizações e organizações de diversos programas específicos, porém, o contexto dos multiletramentos 
são efetivamente tratados com mais profundidade na Base Nacional Comum Curricular (BRASIL, 2018).

O que permeia os multiletramentos, como indica Rojo (2010), é a multissemiose, ou seja, a soma de diversos elementos de sentido, amplificados em variados gêneros textuais, que advêm das expressões da linguagem, seja ela verbal ou não verbal, o que representa a multimodalidade, que integra estes recursos comunicativos (VAN LEEUWEN, 2011). Assim, em Brasil (2018), no tocante à área das linguagens e suas tecnologias, podem ser contemplados como gêneros textuais ascendentes: posts; tweets; gifs; emojis; memes; mashup (mistura entre duas músicas); e-zine; playlist comentada; podcasts; infográficos; reportagens; relatos; tutoriais multimidiáticos; vlog; videominuto; political remix; machinima; anime music video, entre outros, que compõe o mundo do hipertexto na web, relembrando que:

O potencial participativo e colaborativo das TDIC, a abundância de informações e produções requer, ainda, que os estudantes desenvolvam habilidades e critérios de curadoria e de apreciação ética e estética, considerando, por exemplo, a profusão de notícias falsas (fake news), de pós-verdades, do cyberbullying e de discursos de ódio nas mais variadas instâncias da internet e demais mídias (BRASIL, 2018 p. 488).

A alfabetização tornou-se mais complexa, tendo em vista a multimodalidade textual, além da desconstrução pós-estruturalista da linguagem, em Derrida (2001). Conforme o exposto, identifica-se uma inversão de valores, em que a escola precisa reclinar o olhar, assim como suas práticas, para elaborar estratégias concisas, para que os estudantes tenham não somente o domínio da linguagem gráfica e audiovisual; ademais, é necessário, também, que os educandos desenvolvam a percepção crítica destas linguagens do século XXI, das quais ele também faz parte e pode ser afetado por elas. Como estratégia, em 2008, o MEC lançou um Guia de Tecnologias Educacionais, em que estão expostos programas desenvolvidos em algumas cidades brasileiras, em conjunto com grupos de pesquisas de universidades, com a finalidade de inserir a tecnologia na escola com mais efetividade. Assim, o quadro abaixo expõe os principais projetos que propiciavam interações entre a alfabetização e as TDIC até meados de 2010. 
Quadro 1- Projetos que aproximaram a Alfabetização das TDIC

\begin{tabular}{|c|c|}
\hline Projetos & Características \\
\hline $\begin{array}{l}\text { Alfabetização Digital - } \\
\text { Software Livre - Linux }\end{array}$ & $\begin{array}{l}\text { Inclui entendimento e manuseio deste software nas estratégias de } \\
\text { alfabetização; }\end{array}$ \\
\hline $\begin{array}{l}\text { Correção do Fluxo Escolar na } \\
\text { Alfabetização }\end{array}$ & $\begin{array}{l}\text { Estratégias direcionadas a estudantes não alfabetizados em idade } \\
\text { própria, realizado no contra turno; }\end{array}$ \\
\hline Programa Alfa e Beto & $\begin{array}{l}\text { Por meio de uma abordagem sistêmica no aprendizado, acompanha e } \\
\text { disponibiliza materiais que apoiam o professor na fase da alfabetização, } \\
\text { contemplando a diversidade de mídia; }\end{array}$ \\
\hline Programa circuito campeão & $\begin{array}{l}\text { Visa diminuir a defasagem no aprendizado nos três primeiros anos do } \\
\text { ensino fundamental, com estratégias educacionais que dinamizam o } \\
\text { aprendizado; }\end{array}$ \\
\hline Programa se liga & $\begin{array}{l}\text { Desenvolve técnicas e materiais pedagógicos para auxiliar estudantes } \\
\text { com dificuldades na escrita, leitura e cálculo, com foco em estudantes } \\
\text { não alfabetizados; }\end{array}$ \\
\hline $\begin{array}{l}\text { Projeto de Alfabetização } \\
\text { Tecnológica - Kit de Robótica }\end{array}$ & $\begin{array}{l}\text { Fundamenta-se no uso da robótica no desenvolvimento dos conteúdos } \\
\text { curriculares, apoiado em estratégias investigativas, utilizando na } \\
\text { aprendizagem softwares livres, apresentando o sistema de } \\
\text { programação desenvolvido no projeto; }\end{array}$ \\
\hline $\begin{array}{l}\text { Mesa Educacional Alfabeto } \\
\text { Educação Especial }\end{array}$ & $\begin{array}{l}\text { Combina a utilização de computador, leitor e blocos concretos, } \\
\text { adaptados para apoiar a alfabetização de crianças com e sem deficiência } \\
\text { sensorial; }\end{array}$ \\
\hline PRALER & $\begin{array}{l}\text { Programa que desenvolve estratégias aplicadas na alfabetização por } \\
\text { meio de metodologias diferenciadas; }\end{array}$ \\
\hline $\begin{array}{l}\text { Brasil Alfabetizado e Portal } \\
\text { EJA }\end{array}$ & $\begin{array}{l}\text { Estratégias de interação virtual, com foco na alfabetização de jovens e } \\
\text { adultos; }\end{array}$ \\
\hline Sistema Virtus Letramento & $\begin{array}{l}\text { Conjunto de recursos multimídia e software, por meio de aplicações } \\
\text { pedagógicas, para apoiar o desenvolvimento da leitura, produção de } \\
\text { texto e cálculo; }\end{array}$ \\
\hline
\end{tabular}

Fonte: Brasil (2008).

Apesar de as propostas serem promissoras e inovadoras ao aproximar as TDIC no processo de alfabetização, se desenvolveram de maneira isolada, em curtos períodos, além de não comporem a realidade de todas as escolas. Estas estratégias desenvolveram-se com grupos selecionados de alunos e geralmente não ocorreram concomitante ao currículo, ou seja, caracterizam-se como atividades extraclasse ou reforço educacional (NASCIMENTO, 2013). Lopes (2010) organizou, também, um caderno do MEC para professores alfabetizadores, chamado Escola Ativa, o qual implica que, para facilitar o processo de alfabetização, é necessário estabelecer atividades significativas, capacitação docente, valorizar a autoestima dos estudantes, intervir com estratégias fundamentadas e realizar 
diagnósticos da turma, porém não explicita a utilização das TDIC no processo de alfabetização, tão pouco a importância dos multiletramentos.

Neste sentido, Rojo (2017) indica os chamados protótipos didáticos (PD), que demandam estruturas flexíveis e podem ser alterados dependendo do contexto que se quer utilizar; desta forma, podem ser inclusos em propostas didáticas desenvolvidas pelas escolas, no processo de alfabetização. Assim, os diferentes métodos de alfabetização, desenvolvidos e aplicados outrora, vem no século XXI, a convergir, sendo complementados com metodologias de ensino, desenvolvidas em múltiplas áreas, relativas a aspectos cognitivos, como as metodologias ativas.

As metodologias ativas têm como referência ideias que nasceram no século XX e vêm se modificando no século XXI pela presença das TDIC, elaboradas por pesquisadores tanto da Educação quanto de outras áreas. Algumas destas alternativas que podem aproximar professores alfabetizadores dos laboratórios de informática, assim como de outras disciplinas integrando as TDIC nas abordagens pedagógicas, podem as estratégias: design thinking, que adapta no ensino artifícios desenvolvidos por empresas e tipografias do marketing, em busca de alternativas e soluções criativas na construção de conhecimento pelos estudantes (BROWN; WYAAT, 2010); mobile learning, ou m-learning que envolve o uso de dispositivos móveis como celulares/smartphones, tablets e demais dispositivos touch scream, que amplificam a aprendizagem para além da sala de aula, em modelos móveis de aprendizagem (SACCOL, et al., 2010); webblog, que traz a possibilidade de envolver expressões multimodais de diversos gêneros textuais, além de criar uma rede de comunicação virtual e de compartilhamento de conhecimento (MARCUSCHI; XAVIER, 2005); pensamento computacional e letramento computacional, os quais implicam que através do entendimento que se tem sobre o uso dos computadores desenvolvam-se ferramentas, softwares e até mesmo a aplicação da linguagem de programação em computadores $^{4}$ (WING, 2006; DISSESA, 2001); teoria do flow, que se relaciona com o desenvolvimento da gameficação, referente ao estado de atenção e concentração do indivíduo ao imergir no jogo, engajando-se na atividade com maior foco em ultrapassar metas e níveis (CSIKSZENTMIHALY, 1990); ensino híbrido, o qual supões flexibilizar e

\footnotetext{
${ }^{4}$ Algumas alternativas criadas para fins educacionais para iniciantes em linguagem de programação orientada a objetos, é o ambiente de desenvolvimento integrado Pascalzim, Tabulae Colaborativo e Tabulinha, que desenvolvem o pensamento matemático (BRASIL, 2008).
} 
organizar o processo de aprendizagem em um ambiente que concilie o ensino presencial ao online (MORAN; BACICH, 2005); e, nesta mesma perspectiva u-learning ou aprendizagem ubíqua, consistindo em uma aprendizagem onipresente, em qualquer lugar e hora, por meio dos aparatos tecnológicos que nos rodeiam (YAHYA et. al., 2010).

As estratégias acima citadas e as demais, possibilitam desenvolver inúmeras oportunidades de aprendizagem no contexto da alfabetização, seja no seguimento da escrita, ou digitalização, da leitura ou interpretação, trabalhando com diferentes gêneros textuais (multimodalidade), sobre estruturas gramaticais, ortográficas, fônicas e semânticas, que contemplem os multimeios. Estas atividades tornam a práxis mais significativa, engajada e dinâmica à geração alpha, em que os estudantes são protagonistas ativos do processo, conforme Rojo (2017); cria-se, então, um material navegável e interativo, tratados também como objetos digitais de aprendizagem (ODA), como livros digitais sobre o bairro ou a comunidade escolar, HQs temáticas, games, gráficos e infográficos, vidding, entre outros, podendo estar contemplados na elaboração de um webcurrículo, organizado e pensado para alcançar os objetivos da alfabetização.

Embora estas representem novas formas de pensar a educação, embasados em estudos científicos tanto do ocidente quanto do oriente, para fechar a segunda década do século XXI, em 2019, é lançada uma cartilha, aprovada pelo segundo ex-ministro da educação do atual governo, que promove uma reviravolta no campo da alfabetização, aquecida por discursos político-ideológicos, formulada por especialistas brasileiros e estrangeiros, trazendo como referência outro termo para a alfabetização: literacia. Seu desenvolvimento passa, de maneira geral, a ser indicado em três fases: $1^{\mathrm{a}}$ literacia básica, que abrange da pré-escola ao $1^{\circ}$ ano do ensino fundamental, a qual envolve habilidades como decodificação e conhecimento de palavras de alta frequência, fundamentando todas as tarefas de leitura, incluindo a literacia familiar, literacia emergente e alfabetização; $2^{\text {a }}$ literacia intermediária, que abrange do $2^{\circ}$ ao $5^{\circ}$ ano, a qual envolve habilidades comuns da literacia, sendo estratégias de compreensão de textos, significados de palavras, conhecimentos ortográficos e fluência na leitura oral; $3^{\circ}$ literacia disciplinar, que abrange do $6^{\circ}$ ano ao ensino médio, habilidades específicas de diferentes disciplinas.

Apesar de mencionar três fases da literacia, o documento apenas trata de estratégias para a literacia básica, com foco na alfabetização, trazendo também o termo numeracia, sobre a introdução aos conhecimentos básicos da matemática nesta fase 
(BRASIL, 2019). Os pressupostos que passaram a fundamentar a alfabetização são compostos por cinco pontos: $1^{\circ}$ consciência fonêmica; $2^{\circ}$ instrução fônica sistemática; $3^{\circ}$ fluência em leitura oral; $4^{\circ}$ desenvolvimento de vocabulário; e $5^{\circ}$ produção da escrita; além destes cinco componentes, inclui ainda um $6^{\circ}$ em outra parte do texto, referindo-se à adesão de “[...] referenciais de políticas públicas exitosas, tanto nacionais quanto estrangeiras" (BRASIL, 2019, p. 40), porém negligenciam o termo letramento proposto por Soares (2004), multiletramentos indicados por Rojo (2010), e do construtivismo abordado no método Paulo Freire (MORATTI, 2019). Esta política promoveu no primeiro bimestre de 2020, os programas: Conta pra mim, voltado à literacia familiar, para que a família incentive práticas da leitura e Tempo de Aprender, voltados ao aperfeiçoamento de professores alfabetizadores, porém que sofreram interrupções tanto pela pandemia quanto por tensões no governo, não havendo no momento um respaldo sobre a efetividade de ambos.

O ritmo das mudanças ciberculturais não cessa. Tais mudanças são originadas em diferentes processos, de períodos diferentes, porém que se encontram convergentes à geração alpha, que está aprendendo a ler e escrever, envolta nesta complexidade. Apesar dos avanços em integrar a alfabetização com metodologias mais flexíveis, ainda são insuficientes pela instabilidade de concepções que se formulam em relação as TDIC em diferentes documentos educacionais, gerando conforme Nascimento (2013), ainda um contato sistemático, com certa resistência e falta de direcionamento a professores alfabetizadores e de outras áreas a adentrarem no laboratório de informática, desassistidos por políticas educacionais e propostas pedagógicas. Isto caracteriza uma exclusão da geração alpha do processo de se alfabetizar letrando em meios multimodais, somada à negligência político-estrutural ultraconservadora, que se reflete em maiores barreiras, em promover de maneira mais flexível das TDIC neste processo, em modelos que se dizem inovadores, em sintonia com países desenvolvidos, mas que provocam um desmonte educacional, para inglês ver (MORATTI, 2019).

\section{CONSIDERAÇÕES FINAIS}

Em 2020, no momento de pandemia, nunca se esteve tão próximo do que Illich (1985) defendia em meados do século XX; experimentamos em um bom período do ano, uma sociedade sem escolas físicas, com o conhecimento desenvolvido e construído através 
de uma teia educacional, ocorrendo na dimensão ciberespacial. Os ambientes de aprendizagem em nuvem, só foram intensificados, por representar uma estratégia para continuidade dos trabalhos, pela impossibilidade do contato social no momento de pandemia, empregando nas estratégias redes sociais, Google Class, Meet, Zoom, webblog, Skype, e-mail entre outras plataformas, tanto para comunicação quanto para o desenvolvimento de atividades, sem antes, ter sido recomendado, adequado ou até consultado sobre as possibilidades da realização deste formato educativo; culminou-se, assim, em aquecidos discursos sobre acessibilidade, metodologias de ensino remoto, aprendizagem, formação de professores, infraestruturas informacionais, avaliação, currículo, alimentação escolar, entre outros.

Todavia, este modelo não cortou o cordão umbilical de seus antigos métodos. Muitas escolas públicas do Ensino Fundamental, as quais não planejaram em suas estratégias, trabalhar com o conceito de ambientes de aprendizagem em nuvem, seja por razão das infraestruturas insuficientes, pela desarticulação da proposta pedagógica com políticas educacionais, ou questões socioeconômicas das famílias dos estudantes, concisamente optaram por dar continuidade ao modelo que melhor atendesse a maioria dos estudantes, enviando atividades impressas, com cronogramas sobre o plano de trabalho. Na proposta número 5 do Plano Nacional de Educação (PNE) é previsto, até 2024, alfabetizar todos os estudantes até o final do $3^{\circ}$ ano do Ensino Fundamental, e, inclusive, conforme o inciso 5.3, utilizando tecnologias educacionais como um recurso aberto para a alfabetização, tendo em vista a diversidade de métodos, propostas pedagógicas, além do acompanhamento dos resultados (BRASIL, 2019). No entanto, até o momento, não há um documento nacional oficial, um manual ou material didático que direcione o professor alfabetizador, a explorar a alfabetização ou os (multi)letramentos em ambientes virtuais. O que há na literatura brasileira são reflexões e projetos desenvolvidos e adaptados por pesquisadores e professores de maneira isolada. Esse tipo de direcionamento é previsto em documentos educacionais oficiais apenas em Brasil (2018), com estratégias a serem desenvolvidas no ensino médio, utilizando softwares de edição de textos, e audiovisual, por meio de ferramentas colaborativas, para criar textos e produções multissemióticas com finalidades diversas.

Secretarias estaduais e municipais de Educação seguem promovendo formações, como alternativa para recuperar o tempo perdido, pela não articulação das TDIC em suas 
abordagens, não somente com a alfabetização, mas em todos os níveis de ensino. A complexidade e a importância das ações tomadas no agora sobre o futuro da Educação, refletirão incomumente e simultaneamente, em efeitos de curto, médio e longo prazo, representando uma ressignificação de valores, tanto da escola para com a sociedade quanto da sociedade para com a escola, lapidando o olhar da geração alpha, que será responsável por escrever (ou digitar) os próximos capítulos da nossa história.

\section{REFERÊNCIAS:}

BARANAUSKAS, M.C.C.; MARTINS, M.C.; VALENTE, J.A. Prefácio em codesign de redes digitais: tecnologia e educação a serviço da inclusão social. Porto Alegre: Penso, 2013.

BRASIL. [Constituição (1988) ]. Constituição da República Federativa do Brasil de 1988. Brasília, DF: Presidência da República, [2020]. Disponível em: http://www.planalto.gov.br/ccivil_03/constituicao/constituicao.htm. Acesso em: 14 jun. 2021.

BRASIL. MEC. Base Nacional Comum Curricular (BNCC). Educação é a Base. Ensino Fundamental. Brasília: MEC/Secretaria de Educação Básica/CONSED/UNDIME, 2018.

BRASIL. MEC. Diretrizes Curriculares Nacionais da Educação Básica. Brasília: MEC, SEB, DICEI, 2013.

BRASIL. MEC. INEP. Censo escolar da educação básica 2016. Notas estatísticas. Brasília: INEP, 2017.2 Disponível em: http://download.inep.gov.br/educacao_basica/censo_escolar/notas_estatisticas/2017/not as_estatisticas_censo_escolar_da_educacao_basica_2016.pdf. Acesso em: 28 ago. 2020.

BRASIL. MEC. PNA: Política Nacional de Alfabetização. Brasília: MEC, SEALF, 2019.

BRASIL. MEC. Programa de formação de professores alfabetizadores. Guia do Formador. Modulo I e II. Brasília: MEC, SEF, 2001.

BROWN, T.; WYAAT, J. Design thinking for social innovation. Stanford: Stanford Social Innovation Review, v. 8, n. 1. 2010. Disponível em: https://pdfs.semanticscholar.org/3aca/3b6fad54ad77d73b4bb60812a03cff66dfd9.pdf Acesso em: 25 ago. 2020.

CASTELLS, M. A sociedade em rede. São Paulo: Paz e Terra, 1999.

CSIKSZENTMIHALY, M. Flow: the psychology of optimal experience. New York: Harper \& Row, 1990. 
DERRIDA, J. O monolinguísmo do outro ou a prótese de origem. Tradução: Fernanda Bernardo. Porto: Campo das Letras, 2001.

DISESSA, A. A. Changing minds: computers, learning, and literacy. Cambridge: First MIT Press Paperback Edition, 2001.

FERREIRA JR. A. História da educação brasileira: da colônia ao século XX. São Carlos: Editora UFSCAR, 2015.

FERREIRO, E. TEBEROSKY, A. Psicogênese da língua escrita. Porto Alegre: Artes Médicas, 1985.

FRADE, I. C. A. S. Métodos e didáticas de alfabetização: história, características e modos de fazer de professores. Belo Horizonte: Ceale/FaE/UFMG, 2005.

FREIRE, P. A Importância do Ato de Ler: em três artigos que se completam. São Paulo: Cortez / Autores associados, 1989.

ILLICH, I. Sociedade sem escolas. 7. ed. Petrópolis: Vozes, 1985.

LÉVY, P. A inteligência coletiva: para uma antropologia do ciberespaço. Porto: Instituto Piaget, 1994.

LÉVY, P. Cibercultura. 2. ed. São Paulo: Loyola, 1999.

LOPES, J. R. Caderno do educador: alfabetização e letramento 1. Brasília: MEC, SEC, Alfabetização e Diversidade, 2010.

MARCUSCHI, L. A. XAVIER, A. C. Hipertexto e gêneros digitais, novas formas de construção de sentido. Rio de Janeiro: Lucerna, 2005.

MIKROYANNIDIS, A. A semantic framework for cloud learning environments. In: CHAO, Lee ed. Cloud computing for teaching and learning: strategies for design and implementation. Hershey: IGI Global, 2019. p. 17-31. Disponível em: http://oro.open.ac.uk/33220/4/chao_book_Mikroyannidis_chap.pdf. Acesso em: 01 set. 2020.

MORAN, J.M. BACICH, L. Aprender e ensinar com foco na educação híbrida. Revista Pátio, n. 25, p. 45-47. Disponível em: http://www2.eca.usp.br/moran/wpcontent/uploads/2015/07/hibrida.pdf. Acesso em: 29 ago. 2020.

MORATTI, M. R. L. Alfabetização do Brasil: uma história de sua história. Marília: Cultura Acadêmica, 2011.

MORATTI, M. R. L. Brasil 2091: notas sobre a política nacional de alfabetização. Revista Olhares, Guarulhos, v. 7. n. 3, 2019. 
MOREIRA, A. R. M. Considerações sobre o método global de alfabetização. Trabalho de conclusão de curso (Licenciatura em Pedagogia). Distrito Federal: Faculdade de Educação, Universidade de Brasília, 2013. Disponível em: https://bdm.unb.br/bitstream/10483/7373/1/2013_AndressaRejaneMendesMoreira.pdf. Acesso em: 20 maio 2019.

NASCIMENTO, J. K. F. Informática aplicada à educação. Brasília: Universidade de Brasília, 2013.

OLIVEIRA, G. S. Geração alpha entre a realidade e o virtual: o sujeito digital. 2019. Trabalho de conclusão de curso (Bacharelado em Psicologia) - Departamento de Psicologia, Universidade Regional do Noroeste do Estado do Rio Grande do Sul, Unijuí, 2019. Disponível em: https://bibliodigital.unijui.edu.br:8443/xmlui/bitstream/handle/123456789/5811/Genori\%20d a\%20Silva\%20Oliveira.pdf?sequence=1. Acesso em: 20 fev. 2019.

PIAGET, J. Para onde vai a educação? Rio de Janeiro: Unesco, 1973.

PRENSKY, M. Digital natives, digital immigrants - part 1. In: PRENSKY, M. On the horizon. NCB University press, v. 9, n. 5, 2001. p. 1-6.

ROJO, R. Alfabetismo (s), letramento (s), multiletramento (s): desafios contemporâneos à educação de adultos. In: COSTA, R. P.; CALHAU, S. (org.) E uma educação pro povo, tem? Rio de Janeiro: Caetés, 2010.

ROJO, R. Entre plataformas, ODAS e protótipos: novos multiletramentos em tempos de WEB2. The Especialist, v. 38. n. 1, 2017. Disponível em: https://revistas.pucsp.br/index.php/esp/article/view/32219/23261. Acesso em: 14 set. 2020.

SACCOL, A. Z., SCHLEMMER, E., BARBOSA, J. HAHN, R. M-learning e U-learning: novas perspectivas da aprendizagem móvel e ubíqua. São Paulo: Pearson Education, 2010.

SANTOS, M. A natureza do espaço: técnica e tempo, razão e emoção. 4. ed. São Paulo: Universidade de São Paulo, 2009.

SANTOS, M . Réflexions sur le rôle de la géographie dans la période technico scientifique. Cahier de Géographie du Québec, Montréal, v. 32, n. 87, 1988.

SOARES, M. Letramento e alfabetização: as muitas facetas. Revista Brasileira de Educação, $26^{\text {a }}$ Reunião Anual da ANPEd, Poços de Caldas, n. 25, 2004. Disponível em: https://www.scielo.br/pdf/rbedu/n25/n25a01.pdf. Acesso em: 22 set. 2019.

TRIVIÑOS, A. N. S. Introdução à pesquisa em ciências sociais. São Paulo: Atlas, 1987.

THOMAN, E. JOLLS, T. Literacy for the 21st Century: an overview \& orientation-guide to media literacy education. Malibu: Center for Media Literacy, 2003. Disponível em: 
http://www.medialit.org/sites/default/files/01_MLKorientation.pdf. Acesso em: 21 ago. 2020.

UNESCO. Padrões de competências em TIC para professores: módulos de padrão de competências. Brasília: Unesco, 2009.

VAN LEEUWEN, T. Multimodality. In: SIMPSON, J. The routledge handbook of applied linguistics. New York: Routledge, 2011.

WING, J. M. Computational thinking. Communications of the ACM, v. 3, n. 49, 2006. p. 3335. Disponível em: https://www.ncbi.nlm.nih.gov/pmc/articles/PMC2696102/. Acesso em: 28 ago. 2020.

YAHYA, S. AHMAD, E.A. JALIL, K. A. The definition and characteristics of ubiquitous learning: a discussion. IJEDICT, Kingston, v. 6, n. 1, 2010. p. 117-127. Disponível em: https://www.learntechlib.org/p/18806g/. Acesso em: 10 set. 2020.

Recebido em: 22/09/2020

Parecer em: 11/04/2021 Aprovado em: 11/06/2021 